\title{
Bilaterally Fused Supernumerary Kidneys: A Very Rare Case Report and Review of Literature
}

\author{
Alemayehu Tegegne Tefera', Kaleab Habtemichael Gebreselassie (D)', Feysel Hassen Issack (D)', \\ Ashenafi Aberra Buser², Ferid Ousman Mummed (D)', Masresha Solomon Dino', \\ Fitsum Gebreegziabher Gebrehiwot $\mathbb{D}^{\prime}$ \\ 'Department of Surgery, Urology Unit, St. Paul's Hospital Millennium Medical College, Addis Ababa, Ethiopia; ${ }^{2}$ Department of Radiology, St. Paul's \\ Hospital Millennium Medical College, Addis Ababa, Ethiopia \\ Correspondence: Kaleab Habtemichael Gebreselassie, Department of Surgery, Urology Unit, St. Paul's Hospital Millennium Medical College, \\ PO Box 59004, Addis Ababa, Ethiopia, Email Kaleab528@gmail.com; kaleab.habtemichael@sphmmc.edu.et
}

\begin{abstract}
Supernumerary kidney is a rare anomaly of number where commonly a third extra kidney exists with its own collecting system, blood supply, and encapsulated parenchyma. However, an extremely rare and unique diagnosis of bilateral supernumerary kidneys is also reported in few instances where two extra kidneys exist on each side of the body. Parenchymal fusion and the presence of good excretory function make the supernumerary kidneys even rarer as many of the reported cases are rudimentary organs. We present a 35-year-old man with a sudden onset of agonizing right flank pain and tenderness. Radiologic assessment with computed tomography showed bilaterally fussed and malrotated supernumerary kidneys with an obstructive stone and good contrast uptake. The patient has four fully functional kidneys (two on each side) with their own arterial supply, venous drainage, collecting system and incompletely duplicated ureters bilaterally. An open pyelolithotomy is performed to relieve pain and hydronephrosis. The patient's symptoms improved after surgery and during subsequent follow-up.
\end{abstract}

Keywords: bilaterally fused supernumerary kidneys, supernumerary kidney, malrotation

\section{Introduction}

Congenital anomalies of the kidney and urinary tract (CAKUT) are multiple diseases characterized by alterations of embryogenesis with different anatomical origins along the urinary tract. Supernumerary kidney (SNK) is an extremely rare anomaly defined as an extra kidney(s) with its own separate collecting system, blood supply, and capsule. So far, about 80 cases of SNK are reported. Although the common finding is a single extra kidney located caudally to the left of the midline, very rare and unique diagnosis of bilateral SNKs is also reported in up to 6 cases so far and only two reports of bilateral SNKs with urolithiasis exist. ${ }^{1-7}$

Majority of the cases are asymptomatic and the diagnosis is commonly incidental during operations. Occasionally however, SNKs may present with symptoms during childhood or early adulthood due to calculi, tumors, or infections. ${ }^{1,2,8}$ SNKs are also easily missed during cross-sectional imaging due to the fact that the supernumerary unit is often small, dysplastic, and non-enhancing. According to Geisinger, the supernumerary unit may be completely distinct from the native kidney or very rarely fused to it by loose connective tissue. ${ }^{5,6,9}$ In this case report, we present a symptomatic young man with bilaterally fused and malrotated SNKs and an obstructive stone diagnosed by contrast enhanced CT scan.

\section{Case Presentation}

A 35-year-old man presented to the emergency department with a complaint of sudden onset and severe right side flank pain for 6 hours. The pain had colicky nature and radiated to the ipsilateral groin. He reported associated nausea and repeated vomiting since the onset of the pain. There was no report of fever, urine color change or bowel habit alterations. 

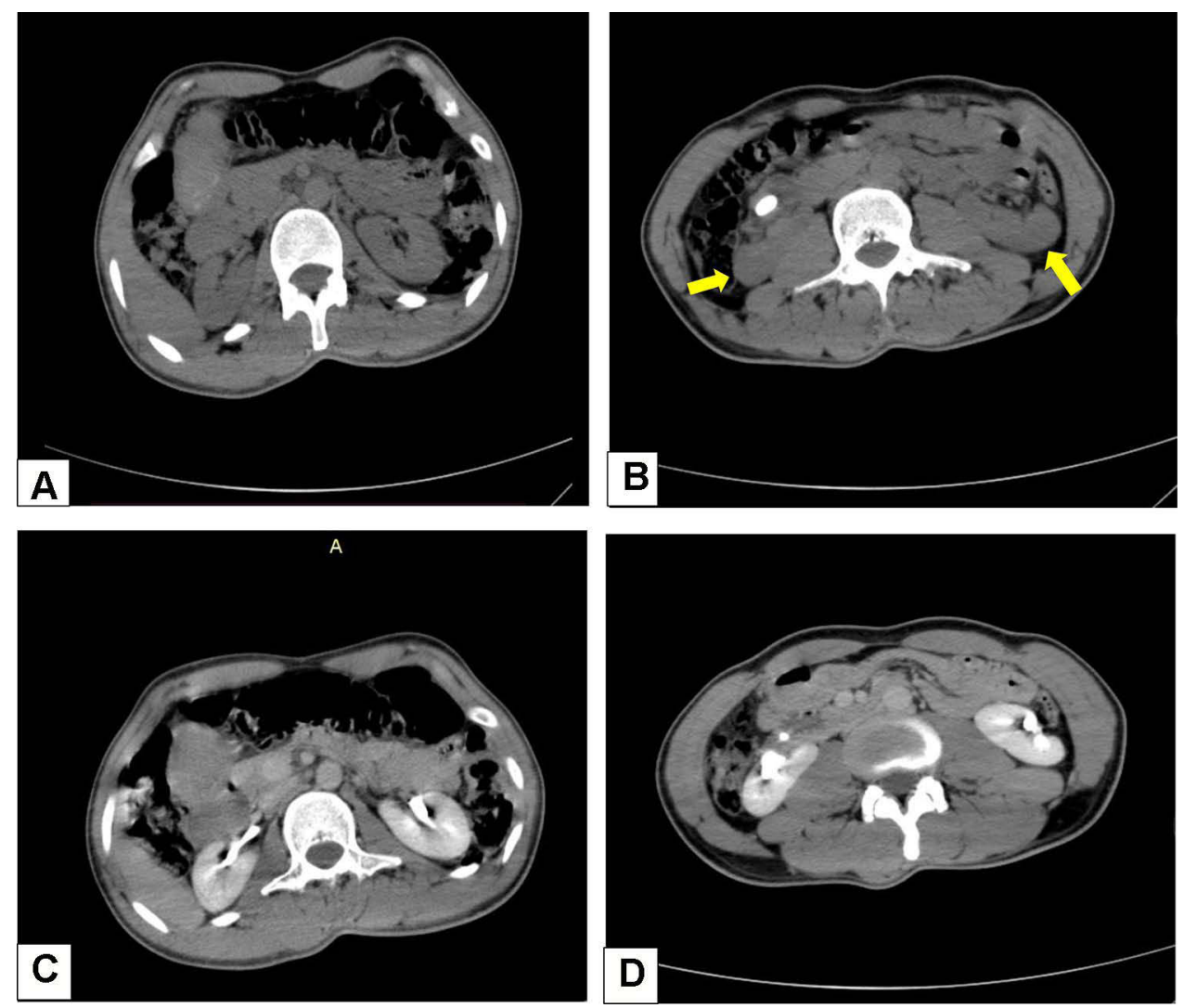

Figure I Non-contrast CT scan showing normal anatomic location of both native kidneys at the level of the first lumbar vertebra (A). Malrotated supernumerary renal units are pointed by yellow arrows at the level of third lumbar vertebra with a solitary stone in the right SNK (B). Good contrast uptake and excretion by both the native (C) and supernumerary renal units (D).

The patient also denied any prior history of similar pain episodes as well as external trauma. The vital signs were all normal. No abnormality was detected on complete physical examination except mild right flank tenderness.

Laboratory work up of urine revealed $>5$ red blood cells per high power field with no pus cells, bacteria, cast or crystals.

The renal and liver function tests as well as complete blood count returned with normal results. With the impression of right ureteric colic and possible obstructive uropathy, intravenous analgesics were administered and a focused bed side ultrasonography (USG) of the abdomen was done and revealed a laterally malrotated right kidney with mild hydronephrosis and hyperechoic focus in the renal pelvis. The radiologist also reported a seemingly elongated right kidney and more than normal number of calyces.

Due to patient discomfort during USG study, characterization of the contralateral kidney was not possible. For this reason, a contrast enhanced CT scan of the abdomen was performed. The result showed the presence of normally located kidneys in their renal fosse with accompanying two additional renal units (one on each side) partially fused with the lower poles of the respective orthotopic kidneys. A $1.9 \mathrm{~cm}$ single stone is also seen within the pelvis of the right SNK. The supernumerary units have separate calyceal systems and renal pelvis with their own vascular supply and venous drainage. All the four renal units have good contrast uptake and timely excretion (Figure 1A-D). Fusion of the renal units occurs bilaterally with an additional antero - lateral rotational anomaly of both SNKs (Figure 2A-C). The right SNK has an arterial supply from the aorta just at its bifurcation while the left one gets its supply directly from the anterior surface of aorta. On the other hand, the right side renal units are drained separately by their respective veins and empty into the IVC (inferior venacava). On the left side, a common venous trunk is formed by the supernumerary and native renal veins and empties into the IVC behind the aorta (retro-aortic common trunk) (Figure 3A-D). A delayed excretory film also showed four separate pelvicalyceal arrangements; one for each renal unit. A confluence of the supernumerary renal pelvis 



Figure 2 Coronal and sagittal reconstruction of contrast enhanced CT scan showing the cleavage of fusion (arrows) between the native and supernumerary kidneys on the right side (A) and left side (B). Antero-lateral rotation of the supernumerary kidneys (arrow heads) and normal anatomic position of the native kidneys is also shown (C).

with its ipsilateral native counterpart is seen on both sides at the level of the uretero-pelvic junction (UPJ) forming bilaterally incomplete ureteral duplication (Figure 4).

Cystoscopy was performed and revealed normal location of ureteral orifices and well-developed trigon. A diagnosis of bilaterally fused supernumerary kidneys and bifid ureters with rotational anomaly and stone is made and the patient was counseled to undergo open stone removal.

After patient consent is obtained, the right renal units were approached via a right subcostal flank incision and pyelolithotomy was done to the lower renal unit without difficulty (Figure 5). The patient had a smooth postoperative course and discharged with improvement.

\section{Discussion}

A SNK is defined as the presence of one or more accessory kidney(s) with its separate capsular covering, pelvicalyceal system and vascular supply. It may be separate from the ipsilateral native kidney or connected to it by a loose areolar tissue in various patterns. The true incidence is unknown but distribution is equal among men and women. Some confusions might arise regarding the naming of a renal unit as SNK. When two kidneys are detected on the same side in the presence of a contralateral kidney, the caudally located and/or the relatively smaller renal unit is generally regarded as being supernumerary. ${ }^{10}$ In most cases of SNK reported so far, there is a smaller third accessory kidney commonly on the left side and caudal to the parenchyma of the native kidney. The maximum number of SNKs reported in the literature is four. The presence of two SNKs (one on each side of the midline) is also very rare and is reported only in 6 cases so far. ${ }^{2-4,7,11}$ The first written documentation about bilateral SNK goes back to 1805 where Voigtel wrote an article about few autopsy findings of four kidneys in humans. ${ }^{12}$

One might encounter a diagnostic confusion between SNK and a duplex kidney, the later one being more common and characterized by renal unit contained within a single capsule with the same (single) vascular supply as the contralateral kidney. ${ }^{3,13}$ The total number of calices in a SNK and the ipsilateral kidney is higher than that of the contralateral kidney. ${ }^{14,15}$ 

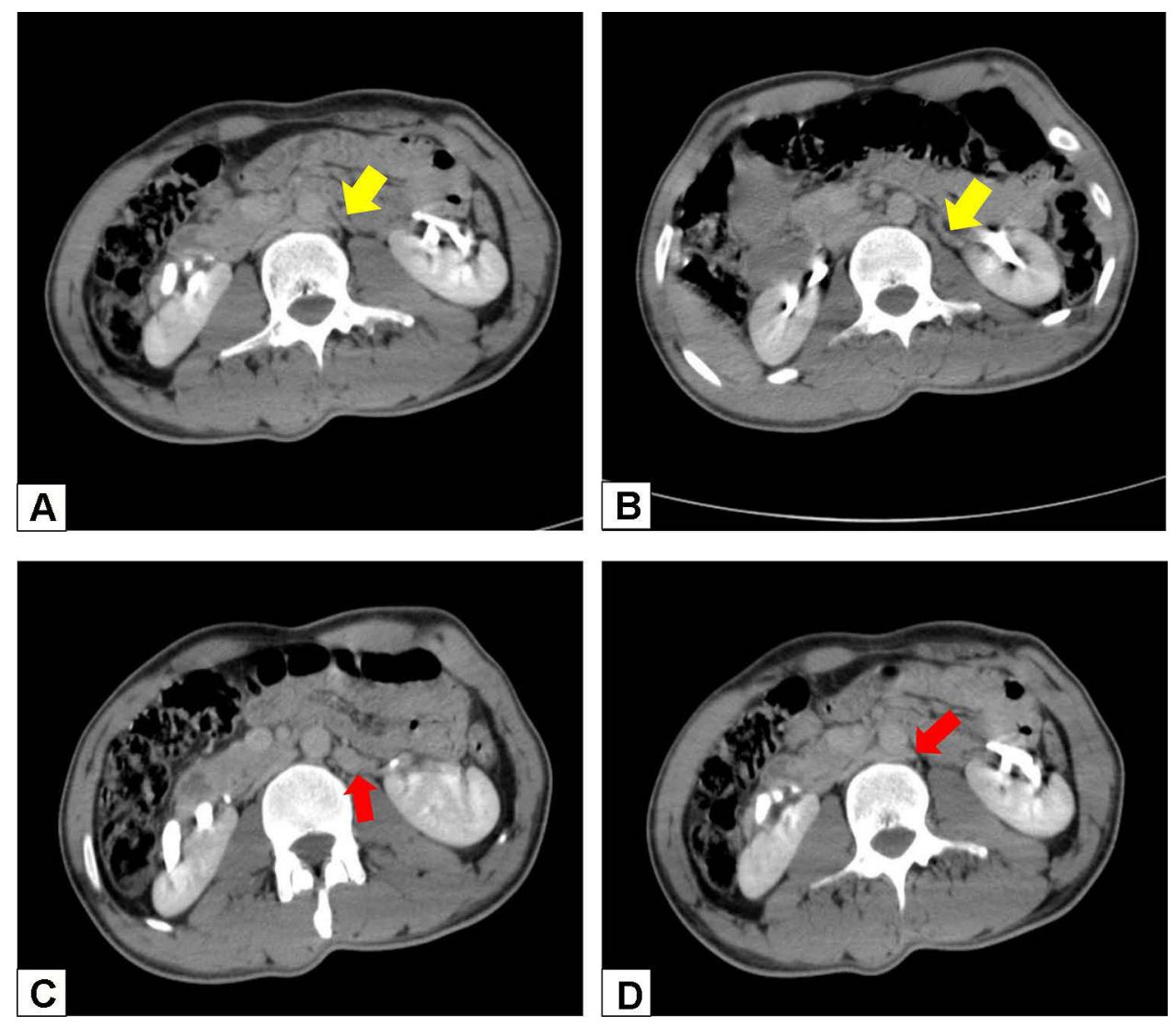

Figure 3 Axial images of abdominal CT scan showing respective vascular anatomy. Yellow arrows indicate separate arterial supplies of the left native (A) and supernumerary kidneys (B) from the aorta; red arrows indicate a common trunk formed by the confluence of individual veins of the left native and SNK (C) and its retro-aortic course (D) towards the IVC.

Joseph F. Geisinger (1937) wrote a comprehensive review of literature regarding 40 patients with this anomaly and characterized SNK as; "a rare scenario that resulted from a lawless embryological sequence", to describe the lack of consistency in its anatomic appearance and physiologic function. ${ }^{9}$ A SNK is often smaller in size and non-functional as compared to its native counterpart. ${ }^{14}$ To the best of our knowledge, bilaterally fused and fully functioning SNK units; as in our case, have not been reported so far.

The vascular distribution of SNKs is very variable and no consistent pattern of arterial origin or venous outflow has been identified so far. Arterial and venous branches from the common iliac, internal iliac and even mesenteric vessels have been reported.

The supernumerary ureter, however, has a relatively predictable pattern as either as an independent pelvis and ureter entering into the bladder ectopically (complete ureteric duplication) or more commonly by fusion with the ureter of the normal kidney entering into the urinary bladder as a single trunk (incomplete ureteric duplication). When SNK is located caudally, a bifid ureter is seen often and the common site of fusion is usually near the bladder. ${ }^{4-17}$ The Weigert-Meyer rule may be followed in SNKs with ectopically located ureteric orifices during entry into the bladder but rare reports of opening near the vagina, cervix, prostatic urethra and vulva also exist. ${ }^{18}$

The embryological development of SNK has been debated in the literature. Normally, a single metanephric blastema is formed within the nephrogenic cord and a single ureteral bud grows towards it from the Wolffian duct, forming a single kidney. However, rarely two metanephric blastemas can be formed from the nephrogenic cord or a single blastema unit can divide in to two units. When these two blastemas are penetrated separately by a bifurcated or double ureteral bud, a SNK is formed. In both cases, a ureteric duplication is common and can be partial or complete. ${ }^{1,2,9,19}$

Bilateral SNKs are formed when this growth pattern occurs on both sides. Anatomic fusion between the normal ipsilateral kidney and the SNK is suspected to occur during division of a single nephrogenic blastema into two 

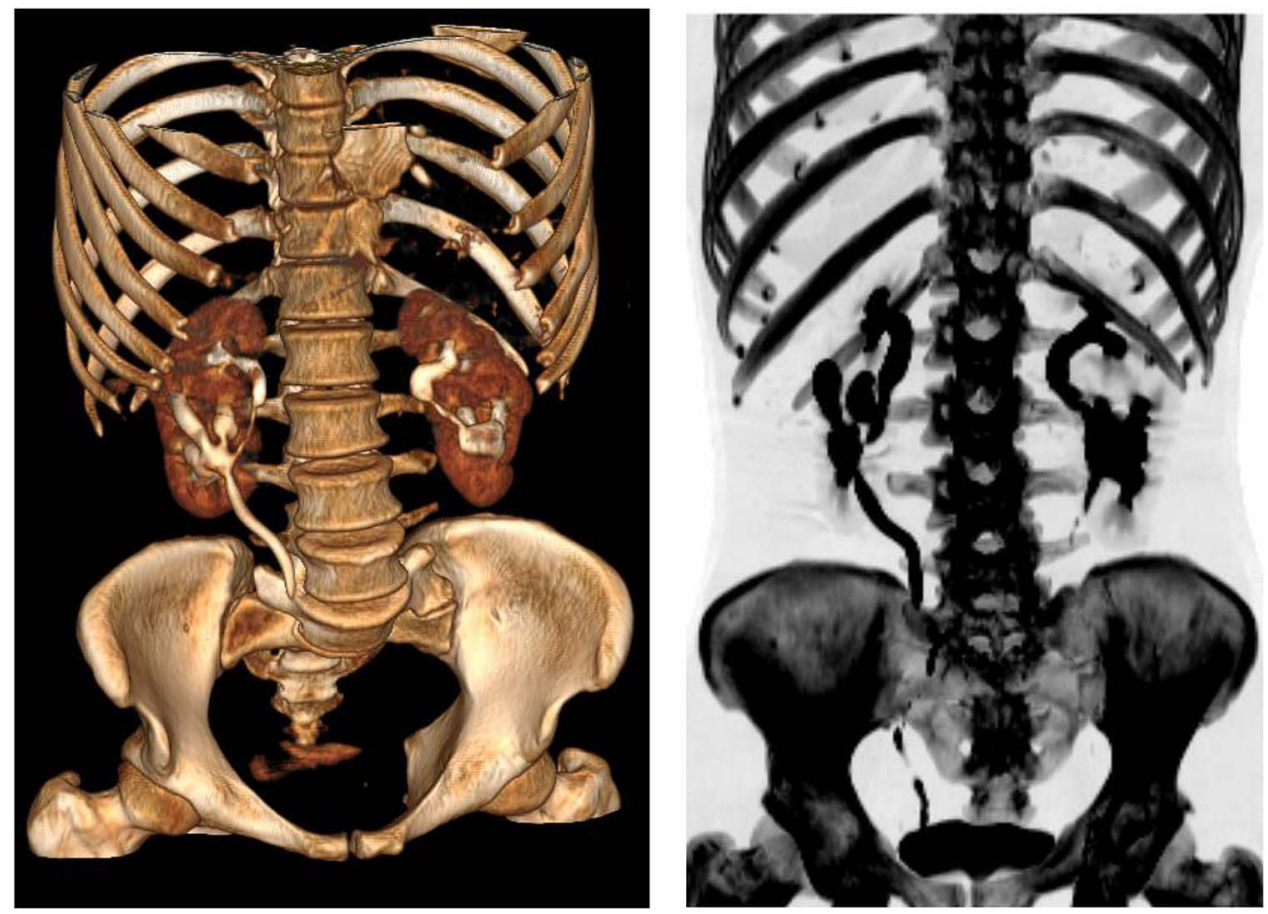

Figure $43 D$ reconstructed images of delayed excretory phase of contrast enhanced CT scan showing adequate excretion of contrast material by all renal units and confluence of each renal pelvis with its ipsilateral counterpart at the level of UPJ bilaterally.
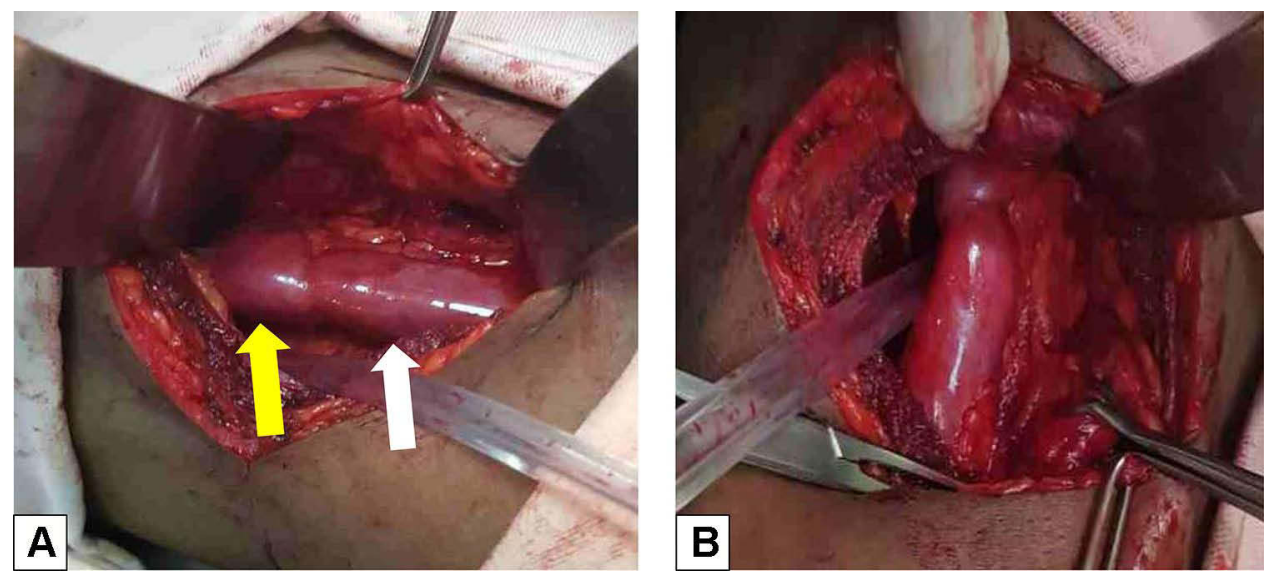

Figure 5 (A) Intraoperative pictures showing an obstructed right SNK (white arrow) fussed with caudal part of the right native kidney (yellow arrow). (B) The supernumerary renal pelvis is accessed posteriorly and pyelolithotomy was done.

units. ${ }^{2,9,17,19}$ Our patient had an additional rotational anomaly of both SNKs likely due to an abnormally late ureteric bud insertion. ${ }^{13}$ No associated anomaly is diagnosed in other organ systems of the patient, but there are reports of concomitant urologic and non-urologic anomalies in patients with SNK. These include: vaginal atresia, urethral duplication, penile duplication, horseshoe kidney, ventricular septal defects, coarctation of aorta, megaureter, imperforate anus, and meningomyelocele. ${ }^{15,19}$

Generally, most renal anomalies are potentially predisposed to pathologic changes such as hydronephrosis, pyonephrosis, stones, cyst, pyelonephritis, hypoplasia, and renal ptosis. Although their pathogenesis is not well elucidated yet, malignant diseases were also reported in few cases such as clear cell carcinoma, Wilms' tumor and upper tract urothelial carcinoma. Furthermore, SNKs can be subject to trauma. ${ }^{11,13,14}$ 
Our patient had a solitary secondary stone in the pelvis of the right supernumerary unit likely due to the urine stasis induced by the associated rotational anomaly.

SNKs are usually asymptomatic and discovered as an incidental finding. In some instances, autopsy records were the means to diagnosis. However, in some patients, nonspecific symptoms such as palpable abdominal mass, pain, fever or hypertension may occur. Pain appears to be the most constant presentation among the symptomatic SNK cases reported but was very variable in location, duration, and general characteristics. Geisinger reported one instance when the SNK was on the left side but the pain was on the right. In other rare reports, the SNK has been found to be normal and patient symptoms were due to stone in the anatomically normal kidney. ${ }^{9,12}$

Stones have also been found in both normal and SNK units. The pain complained by our patient was attributed to an impacted stone in the pelvis of the right SNK and not merely due to the anomaly itself. As it is also stated in many other reports, a clinical history or physical examination findings appear to never suggest the diagnosis of SNK and the large majority of cases are diagnosed incidentally during open surgery or autopsy. Most cases of SNK have appeared as a surprise to the surgeon. ${ }^{5,8,9}$

Preoperative diagnosis of SNK has been reported in few cases using imaging modalities such as Intravenous Urography (IVU), CT scan, radionuclide imaging, and magnetic resonance imaging (MRI). However, the diagnostic yield of some of these imaging modalities such as IVU will entirely depend on the functionality of the SNK. In this regard, retrograde pyelograms can be useful. ${ }^{5,6,19}$ In our patient, the presence of functionally intact SNKs with good excretory function assisted in the preoperative diagnosis. MRI and CT angiography can also be used to better characterize the vascular and ureteral anatomy. ${ }^{4}$ To the best of our knowledge, this is the first case of bilateral SNK with a retro-aortic native left renal vein arrangement.

The treatment of SNKs is individualized and no standard protocol exists. In most reported cases, asymptomatic patients with incidentally diagnosed SNKs can be simply observed and reassured. However, they should be evaluated for the concomitant presence of other anomalies and require regular follow-up with laboratory as well as imaging studies. ${ }^{3,7}$

Follow-up evaluation with yearly ultrasonography can be performed and other imaging studies can be reserved for symptomatic cases. ${ }^{1,3,20,21}$

On the other hand, complicated SNKs can be managed differently depending on the circumstances. SNKs with infection, pain, non-obstructing stones, and minimal hydronephrosis can be initially treated conservatively with antibiotics and analgesics. Open supernumerary nephrectomy or uretero - nephrectomy can be considered in cases of malignancy, severe or repeated infection and multiple stones. A laparoscopic approach is also reported as an option of surgical removal. ${ }^{1,2,4,5,16,20}$ We treated our patient with right SNK pyelolithotomy to relieve the obstructive and pain. Further radical procedure is deferred due to the acceptable size and intact functionality of the right SNK.

\section{Conclusion}

SNKs are in general epidemiologically rare and bilateral SNKs are the rarest with only few cases reported so far. Most are asymptomatic and the diagnosis is often made incidentally during operation and rarely during imaging studies. Crosssectional imaging with CT scan or MRI can aid in the diagnosis. Often, SNKs have no parenchymal communication with their ipsilateral native counterparts and exist with their own capsule. Fusion between a native and a SNK is rarely identified. Additionally, most SNKs are deprived of functionality but rather exist as rudimentary organs. The diagnosis of two functional SNKs as evidenced by contrast uptake on CT imaging is surprisingly uncommon. Regular follow-up is recommended in all patients with SNKs as there is a risk of developing complications in some patients such as hydronephrosis, pyelonephritis, stone formation, and malignancy in either the supernumerary or the native renal unit. Associated genital, cardiovascular, and musculoskeletal defects can also co-exist.

There is no generally valid recommendation regarding treatment of SNKs. However, the consensus is that each therapeutic decision should be tailored to the individual circumstances.

\section{Abbreviations}

CAKUT, congenital anomalies of kidney and urinary tract; SNK, supernumerary kidney; USG, ultrasonography; CT, computed tomography; IVC, inferior venacava; MRI, magnetic resonance imaging; IVU, intravenous urography; UPJ, uretero-pelvic junction. 


\section{Data Sharing Statement}

Data sharing is not applicable to this article as no datasets were generated or analyzed during the current study.

\section{Consent for Publication}

An institutional approval was not required to publish the report details. However, a written and signed informed consent was obtained from the patient for the publication of this case report and accompanying images.

\section{Author Contributions}

All authors made a significant contribution to the work reported, whether that is in the conception, study design, execution, acquisition of data, analysis and interpretation, or in all these areas; took part in drafting, revising or critically reviewing the article; gave final approval of the version to be published; have agreed on the journal to which the article has been submitted; and agreed to be accountable for all aspects of the work.

\section{Funding}

There is no funding to report.

\section{Disclosure}

The authors report no conflicts of interest in this work.

\section{References}

1. Kati B, Gümüş K, Turan U. Supernumerary kidney stone presenting as abdominal pain and hematuria: case report. Turkiye Klinikleri J Urol. 2015;6 (1):20-22. doi:10.5336/Urology.2015-43756

2. Patel R, Singh H, Willens D, Drake S. Bilateral supernumerary kidneys: how much is too much? Case Rep. 2014;2014:bcr2013202677.

3. Yisau AA, Sa'ad AT, Ahidjo A, Ajape AA. Bilateral supernumerary kidneys: incidental finding in a three-month-old infant. Afri J Urol. 2010;16 (2):46-48. doi:10.1007/s12301-010-0010-y

4. Keskin S, Batur A, Keskin Z, Koc A, Ozcan IF. Bilateral supernumerary kidney: a very rare presentation. Iran J Radiol. 2014;11(4). doi:10.5812/ iranjradiol.11069

5. Rehder P, Rehwald R, Böhm JM, et al. Supernumerary kidneys: a clinical and radiological analysis of nine cases. BMC Urol. 2019;19(1):1-8. doi:10.1186/s12894-019-0522-0

6. Carlson HE. Supernumerary kidney: a summary of fifty-one reported cases. $J$ Urol. 1950;64(2):224-229. doi:10.1016/S0022-5347(17)68623-3

7. Chien JC, Chan WP. Bilateral supernumerary kidney. J Korean Med Sci. 2016;31(5):822-823. doi:10.3346/jkms.2016.31.5.822

8. Gao X, Xing Q, Luo X, et al. Right supernumerary kidney with urothelial carcinoma: a case report. Medicine. 2020;99(38):e22329.

9. Geisinger JF. Supernumerary kidney. J Urol. 1937;38(4):331-356. doi:10.1016/S0022-5347(17)71961-1

10. Pintér AB, Schäfer J, Varró J. Two supernumerary kidneys with ureteral atresia. J Urol. 1982;127(1):119-120. doi:10.1016/S0022-5347(17)536368

11. Mustafa M. Bilateral supernumerary kidneys in conjunction with horseshoe anomaly. Saudi J Kidney Dis Transplant. 2012;23(6):1243. doi:10.4103/1319-2442.103568

12. Saccone A, Hendler HB. Supernumerary kidney. Report of a case and a review of the literature. $J$ Urol. 1934;31(5):711-720. doi:10.1016/S00225347(17)72431-7

13. Mebis W, Peters B, van der Zijden T. S-shaped kidney: a rare occurrence of supernumerary kidney with fusion-malrotation. $J$ Belgian Soc Radiol. 2018;102(1). doi:10.5334/jbsr.1666

14. Tada Y, Kokado Y, Hashinaka Y, et al. Free supernumerary kidney: a case report and review. J Urol. 1981;126(2):231-232. doi:10.1016/S00225347(17)54457-2

15. Suresh J, Gnanasekaran N, Dev B. Fused supernumerary kidney. Radiol Case Rep. 2011;6(4):552. doi:10.2484/rcr.v6i4.552

16. Innocenzi M, Casale P, Alfarone A, et al. Supernumerary kidney laparoscopically treated. Can Urol Assoc J. 2013;7(11-12):E772. doi:10.5489/ cuaj. 788

17. Favorito LA, Morais AR. Evaluation of supernumerary kidney with fusion using magnetic resonance image. Int Braz J Urol. 2012;38(3):428-429. doi:10.1590/S1677-55382012000300018

18. Shane JH. Supernumerary kidney with vaginal ureteral orifice. J Urol. 1942;47(3):344-347. doi:10.1016/S0022-5347(17)70814-2

19. Moreno VG, Coruña MC. Imaging of anatomic variations in a case of supernumerary kidney. J Med Res. 2018;4(2):82-84. doi:10.31254/ jmr.2018.4205

20. Chawla A. Refluxing supernumerary kidney: easy to overlook. Case Rep. 2014;2014:bcr2013201163.

21. Oto A, Kerimoğlu U, Eskicorapci S, Hazirolan T, Tekgül S. Bilateral supernumerary kidney: imaging findings. JBR-BTR. 2002;85(6):300-303. 


\section{Publish your work in this journal}

The International Medical Case Reports Journal is an international, peer-reviewed open-access journal publishing original case reports from all medical specialties. Previously unpublished medical posters are also accepted relating to any area of clinical or preclinical science. Submissions should not normally exceed 2,000 words or 4 published pages including figures, diagrams and references. The manuscript management system is completely online and includes a very quick and fair peer-review system, which is all easy to use. Visit http://www.dovepress.com/testimonials. php to read real quotes from published authors.

Submit your manuscript here: https://www.dovepress.com/international-medical-case-reports-journal-journal 